\title{
Formulation of a Nutrient-Rich Complementary Biscuit for Children Between Eight Months and Fifty Nine Months
}

\author{
Kembabazi Stellamaris ${ }^{1}$, Mutambuka Martin ${ }^{2}$, Marta Vicente-Crespo ${ }^{3,4,}$, \\ ${ }^{1}$ Faculty of Biomedical Sciences, Kampala International University, Ishaka-Bushenyi, Uganda \\ ${ }^{2}$ Nutrition and Biosystems Engineering, Makerere University, Kampala, Uganda \\ ${ }^{3}$ Institute of Biomedical Research, Kampala International University Western Campus, Ishaka, Uganda \\ ${ }^{4}$ Department of Biochemistry, St. Augustine International University, Kampala, Uganda \\ Email address: \\ kembabazi.stella@gmail.com (K. Stellamaris),mcmutambuka@gmail.com (M. Martin), \\ mvicentecrespo@mzimainternational.org (M. Vicente-Crespo) \\ ${ }^{*}$ Corresponding author
}

\section{To cite this article:}

Kembabazi Stellamaris, Mutambuka Martin, Marta Vicente-Crespo. Formulation of a Nutrient-Rich Complementary Biscuit for Children Between Eight Months and Fifty Nine Months. International Journal of Food Science and Biotechnology. Vol. 3, No. 1, 2018, pp. 33-39. doi: $10.11648 /$ j.ijfsb.20180301.15

Received: January 23, 2018; Accepted: February 6, 2018; Published: March 21, 2018

\begin{abstract}
Low breast feeding rates, early introduction of complementary foods, heavy workload of the care givers, lack of ready-to- prepare formulations and the infrequency of feeding of the weaned children are the major causes of Protein Energy Malnutrition in western Uganda. The common complementary foods in Ugandan rural areas are staple cereals gruels and porridges which have low energy density with low animal-protein intake. The study aimed at formulating a nutrient-rich biscuit from locally available materials with the potential to mitigate undernutrition. A low water content biscuit with high energy density and recommendable shelf-life stability under domestic storage conditions was baked from locally available food materials with a composite flour of $24 \%$ soya bean flour, $20 \%$ pumpkin seed flour, $32 \%$ banana flour and $24 \%$ wheat flour. Biscuit servings of $66 \mathrm{~g}, 77 \mathrm{~g}, 110 \mathrm{~g}$ and $132 \mathrm{~g}$ were sufficient to meet above $50 \%$ of the RDA for infants of 8 months to 12 months, 12 months to 24 months, 24 to 48 and 48 to 59 months old children respectively.
\end{abstract}

Keywords: Biscuit, Undernutrition, Complementary Foods, Children

\section{Introduction}

In Uganda, malnutrition is the underlying cause of as many as $45 \%$ of the child deaths; rates of anaemia and Vitamin A deficiency are especially alarming affecting almost half of children under 5 [1]. In western Uganda, the levels malnutrition as measured by the levels of stunting are alarmingly high at $46 \%$ [2]. The low breast feeding rates, early introduction of complementary foods, heavy workload of the care givers, lack of ready-to-eat formulations and the infrequency of feeding of the weaned children have been established as the leading causes of Protein Energy Malnutrition [3, 4]. The common complementary foods given to the weaned children are gruels and porridges from staple cereals which have low energy density with low rates of introduction of animal products like meat and eggs [5].

Kwashiorkor and Marasmus are the two forms of PEM differentiated by the presence or absence of edema respectively [6].

In addition to PEM, the most prevalent and clinically manifested micronutrient deficiencies in children under five include: iron, iodine, zinc, and vitamin $\mathrm{A}$ and $\mathrm{B}_{12}$ [7]. There are various therapeutic foods which have been used in the management of acute mal-nutrition in children because these foods are formulated to contain not only adequate amounts of all the nutrients required by undernourished children, but are also energy dense with a high digestibility [8]. However, the RUFTs that don't use locally available materials are costly and not readily available for the rural mothers [9]. Utilization 
of local ingredients to produce a RUTF in a country or region by combining the staple foods in proper proportions should not only provide nutrients to weaned children but also reduce the total cost of production. Affordable formulas prepared from local food materials are, therefore, vital for management of child under-nutrition in developing countries [9].

\section{Materials and Methods}

\subsection{Sample Collection}

Fresh mature bunches of bananas (Mbwazirume) were obtained from Ishaka market, Bushenyi district, Western Uganda, kept at room temperature for two days, to allow ripening, peeled, sliced and soaked into 5litres of freshly prepared lemon juice for 15 minutes: to prevent oxidation. The pulp was then oven dried for 12 hours at $60^{\circ} \mathrm{C}$ using a hot air oven Binder ED 53. The dry chips were then milled using a laboratory miller KIKA-WERKE M20 and flour kept in a black polyethene bag at room temperature till use.

Pumpkins were obtained from Kabwohe market, Sheema district, Western Uganda, cut and seeds removed. The seeds were washed in clean tap water and sun dried for two days. The dry seeds were then roasted at $60^{\circ} \mathrm{C}$ for 15 minutes. They were then milled into powder using a laboratory miller KIKA-WERKE M20.

Mature harvested soya beans were bought from Kabwohe market, Sheema district, Western Uganda, sorted, to remove seeds with damaged cotyledons. The seeds were soaked in clean water in a vessel that could contain twice the volume of water used; this was done to reduce the content of phytates in the legumes. They were left for an overnight while the water was changed thrice. The soya beans were then sundried for a week, roasted at $60^{\circ} \mathrm{C}$ for 90 minutes and milled into powder using laboratory miller KIKA-WERKE M20. The flour was then kept in a sealed polyethene bag at room temperature till use.

Eggs were obtained from local hens reared using a freerange system from Sheema, Western Uganda.

Carrots were obtained from Ishaka market. Milk was bought from a local farmer of local Ankole cows in Bushenyi, Western Uganda.

\subsection{Formulation}

With the goal of obtaining a biscuit that met $50 \%$ of the RDA for Zinc, Iron, Vitamin A, Vitamin $\mathrm{B}_{12}$, protein and energy, the raw ingredients were mixed in proportions expected to add up to quantities well above of the 50\%RDA when possible. The RDA values were obtained from the National Academy of Sciences [10]. The nutrient composition of the different food materials considered was obtained from the USA Department of Agriculture [10] and used to generate a theoretical content of each of the micro and macro nutrients in $100 \mathrm{~g}$ of food material.

These values were used to select ingredients that were rich in the target nutrients according to the objective of meeting the RDA for the micro- and macro-nutrients for which there is deficiency in Western Uganda.

Ingredients were selected taking into consideration the feasibility of including them into a bake-able dough. After all the baking trials and modifications, the theoretical (expected) nutritional value of the raw dough and the biscuit were calculated considering the nutritional facts of USDA, 2008 to meet in excess the goal of $50 \%$ of RDA of all age brackets, since it was expected to have some baking losses.

A biscuit was baked from $24 \%$ soya bean flour, $20 \%$ pumpkin seed flour, $32 \%$ banana flour and $24 \%$ wheat flour, vitamin A fortified margarine (baking fat), 50\% granulated sugar and 50\% icing sugar (baking sugar) using GR series automatic gas oven ISO90001 standard.

\subsection{Proximate Analyses}

\subsubsection{Determination of Protein}

The amount of protein was determined using Kjeldahl's method according to AOAC (1999) method number 984.13.

$1 \mathrm{~g}$ of the sample was digested in concentrated sulphuric acid with one Kjeldahl tablet in a Tecator digestion system. This was followed by distillation in $40 \%$ sodium hydroxide in a Kjeltec 2300 Auto analyzer. The resultant solution was titrated against $0.1 \mathrm{~N}$ hydrochloric acid using mixed indicator (methyl red and bromocresol green). The protein content was obtained using the conversion factor of 6.25 .

\subsubsection{Determination of Fat}

The amount of fat was determined using petroleum ether extraction using Soxtec system 1043 Extraction unit method number 996.06. Pre-dried and labeled fat extraction beakers were weighed.

$2.5 \mathrm{~g}$ of moisture-free biscuit sample was weighed into labeled extraction thimbles.

Fat extraction beakers were filled with $50 \mathrm{~mL}$ of petroleum ether and attached to the unit. The thimbles were immersed in the extracting solvent for 25 minutes, rinsed for 50minutes and dried in vacuum oven for 45 minutes to allow the evaporation of petroleum ether. The beakers were then allowed to cool from the desiccator.

The total fat was obtained as follows;

$$
\% \text { Total Fat }=\frac{\text { Weight of extracted fat }}{\text { Weight of dry sample }} \times 100
$$

\subsubsection{Determination of Total Carbohydrate}

Total carbohydrate was determined using the phenolsulphuric acid method as described by Agrawal et al, (2015). 2.5g of the sample was digested using cold acetone, hydrolysed using sulphuric acid and phenol added as a colouring agent. The absorbance was taken at $470 \mathrm{~nm}$.

\subsubsection{Mineral Analysis}

\section{(a) Iron and Zinc}

The iron and zinc content of the biscuits was determined using Atomic Absorbance Spectrophotometer (AAS) Perkin 
Elmer Norwalk, CT, USA as described by AOAC (20005b) method number 975.03. $5 \mathrm{~g}$ of the sample were milled into powder, digested using concentrated nitric acid and hydrogen peroxide, the amounts of minerals determined at $259.9 \mathrm{~nm}$ and $213.9 \mathrm{~nm}$ for iron and zinc respectively using airacetylene flame.

\subsubsection{Vitamins}

\section{(a) Beta carotene determination}

Beta-carotene was determined according to Harvest Plus method [11] using UV-visible spectrophotometer (PerkinElmer, Lambda Bio 20, USA).

$2.5 \mathrm{~g}$ of the Samples was weighed and transferred into a mortar, mixed with cold acetone and then filtered into a 50 $\mathrm{ml}$ volumetric flask. The extract was transferred into a $500 \mathrm{ml}$ separating funnel and petroleum ether $(300 \mathrm{ml})$ added. Distilled water $(30 \mathrm{ml})$ was added slowly along the walls of the separating funnel. Samples were left to stand at room temperature allowing the two phases to separate and the lower aqueous phase discarded. The mixture was washed four times to remove residual acetone. In the last washing, the lower phase was discarded and the petroleum ether phase collected in a $50 \mathrm{ml}$ volumetric flask through anhydrous sodium sulphate. The volume was then made to the mark with hexane and absorbance taken at $450 \mathrm{~nm}$. Vitamin A was obtained as Retinol Activity Equivalency (RAE) by dividing the total carotenoids obtained by 12 .

(b) Vitamin $B_{12}$
Vitamin $\mathrm{B}_{12}$ extraction was done using water and enzymes pepsin and amylase. The analysis was done using a High Performance Liquid Chromatography (HPLC) SERIES 200 DAD with $35 \%$ methanol and $65 \%$ potassium hydrogen phosphate as the mobile phase using columns of Sunfire C 18 3.5 with a column diameter of 4.0 .

\subsubsection{Energy Density}

The energy density was calculated according to the Atwater factors; with energy density of fat $(9 \mathrm{kcal} / \mathrm{g})$, protein and carbohydrate (4 kcal/g) [12].

\subsubsection{Shelf Life Stability}

Each of the three independently baked biscuit samples were stored for a period of 14 days in a closed cupboard at room temperature, placed in between two petri dishes. These storage conditions are a mimic of domestic storage conditions. Moisture content and water activity monitored upon storage.

\subsubsection{Moisture Content}

Moisture content was determined using a hot box oven with fan size 2 AOAC (2000) method number 925.40. Samples were weighed $(5 \mathrm{~g})$ in dry Petri dishes and heated in an electric oven at $105^{\circ} \mathrm{C}$ for 12 hours.

Dried samples were cooled in the desiccators, and the weight taken. The difference in weight was then obtained.

Moisture content (MC) was obtained as follows:

$$
\mathrm{MC}=\frac{\text { Weight of ashed sample }+ \text { Crucible }- \text { Weight of crucible }}{\text { Weight of wet sample }+ \text { Crucible }- \text { Weight of crucible }} \times 100
$$

\subsubsection{Water Activity}

Water activity was measured using a Rotronic apparatus type Hygroskop DT water activity analyzer at temperatures of $25 \pm 5^{\circ} \mathrm{C}$. The biscuit samples were milled and the powder analyzed for water availability.

\section{Results and Discussion}

\subsection{Nutritional Analysis}

Table 1. Nutritional analysis per $100 \mathrm{~g}$ of the biscuits and Number of biscuits required to meet the $50 \%$ RDA for the different micro and macro-nutrients for the target age groups.

\begin{tabular}{|c|c|c|c|c|c|}
\hline \multirow{2}{*}{ NUTRIENT } & \multirow{2}{*}{ OBTAINED VALUE PER 100g BISCUIT } & \multicolumn{4}{|c|}{ Number of biscuits required to meet the $50 \%$ RDA } \\
\hline & & 8 to 12 months & 12 to 24 months & 24to 48months & 48to 59months \\
\hline Protein $(g)$ & $9.07 \pm 0.58$ & 1.94 & 3.6 & 4.8 & 5.8 \\
\hline Fat $(g)$ & $26.07 \pm 1.25$ & 3.5 & 3.8 & 4.1 & 4.3 \\
\hline Carbohydrate (g) & $52.04 \pm 2.39$ & 6.8 & 6.7 & 6.8 & 6.7 \\
\hline Gross energy (Kcal) & $448.63 \pm 1.96$ & 3.6 & 3.6 & 7.3 & 7.8 \\
\hline Iron (mg) & $4.46 \pm 0.22$ & 5.3 & 5.3 & 5.3 & 5.3 \\
\hline Vitamin A $(\mu \mathrm{g})$ & $109.62 \pm 4.05$ & 7.8 & 8.0 & 8.3 & 10.3 \\
\hline Vitamin $B_{12}(\mu \mathrm{g})$ & $0.26 \pm 0.67$ & 4.3 & 6.1 & 7.4 & 6.1 \\
\hline
\end{tabular}

The nutritional analysis is summarized below (Table 1), with the average weight of a biscuit obtained as $22 \pm 0.5 \mathrm{~g}$, the number of biscuits required to meet theoretically the $50 \%$ RDA of infants for the target groups was obtained as shown below (figure 1).
Given the obtained nutritive values of the biscuits serving portions of $3,3.5,5$ and 6 are recommended for age groups 8 months to 12 months, 12 to 24 months, 24 to 48 months and 48 to 59 months respectively (figure 1 ). 


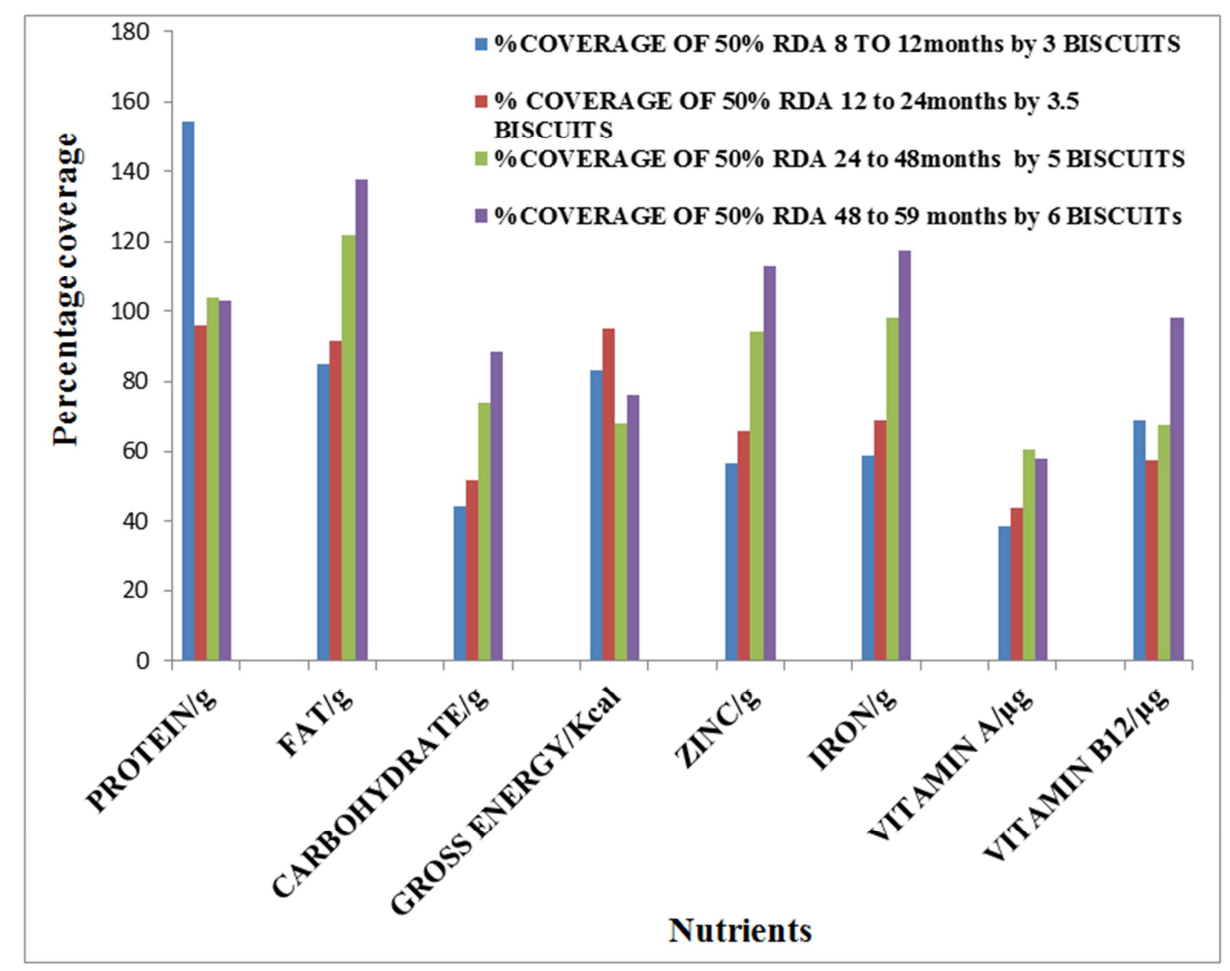

Figure 1. Percentage coverage of 50\% RDA for the target groups by recommended biscuit portions.

\subsection{Shelf-Stability}

\subsubsection{Moisture Content}

The moisture content of biscuits increased steadily as storage progressed (Figure 2).

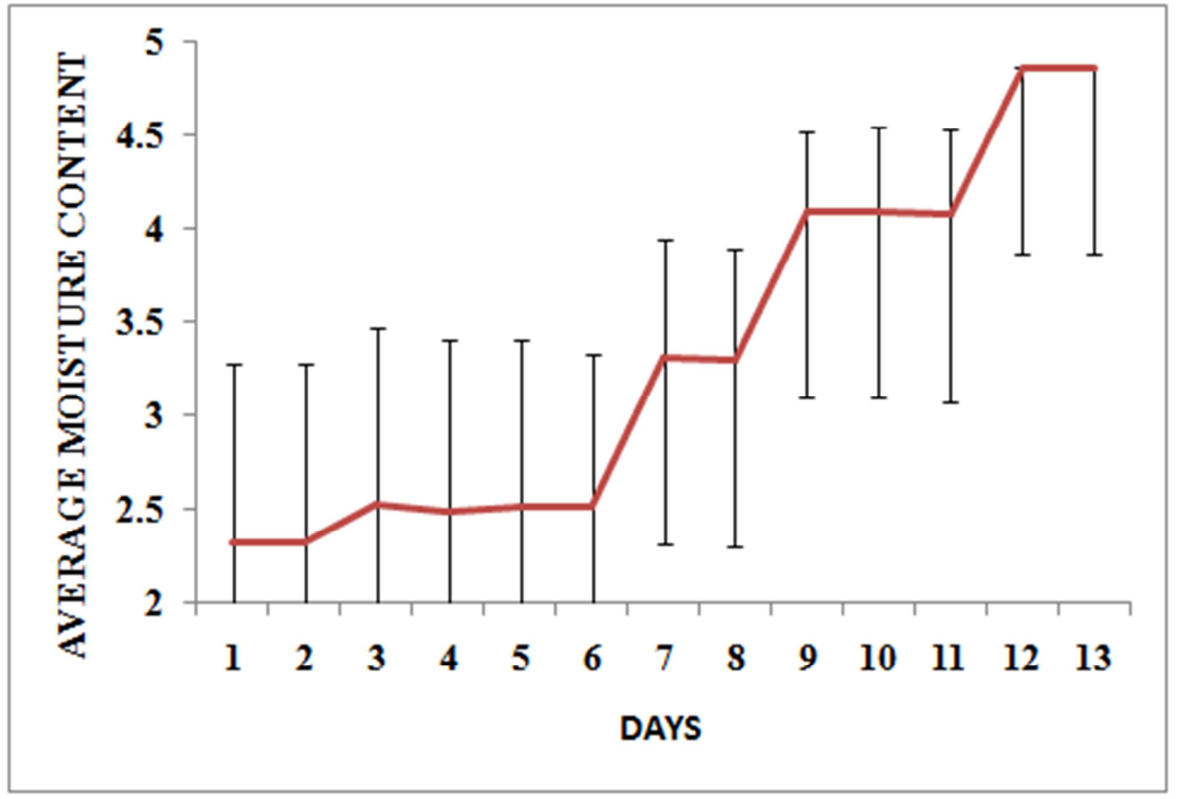

Figure 2. The moisture content of the stored biscuits.

\subsubsection{Water Activity}

The water activity of biscuits decreased steadily as storage progressed (Figure 3) 


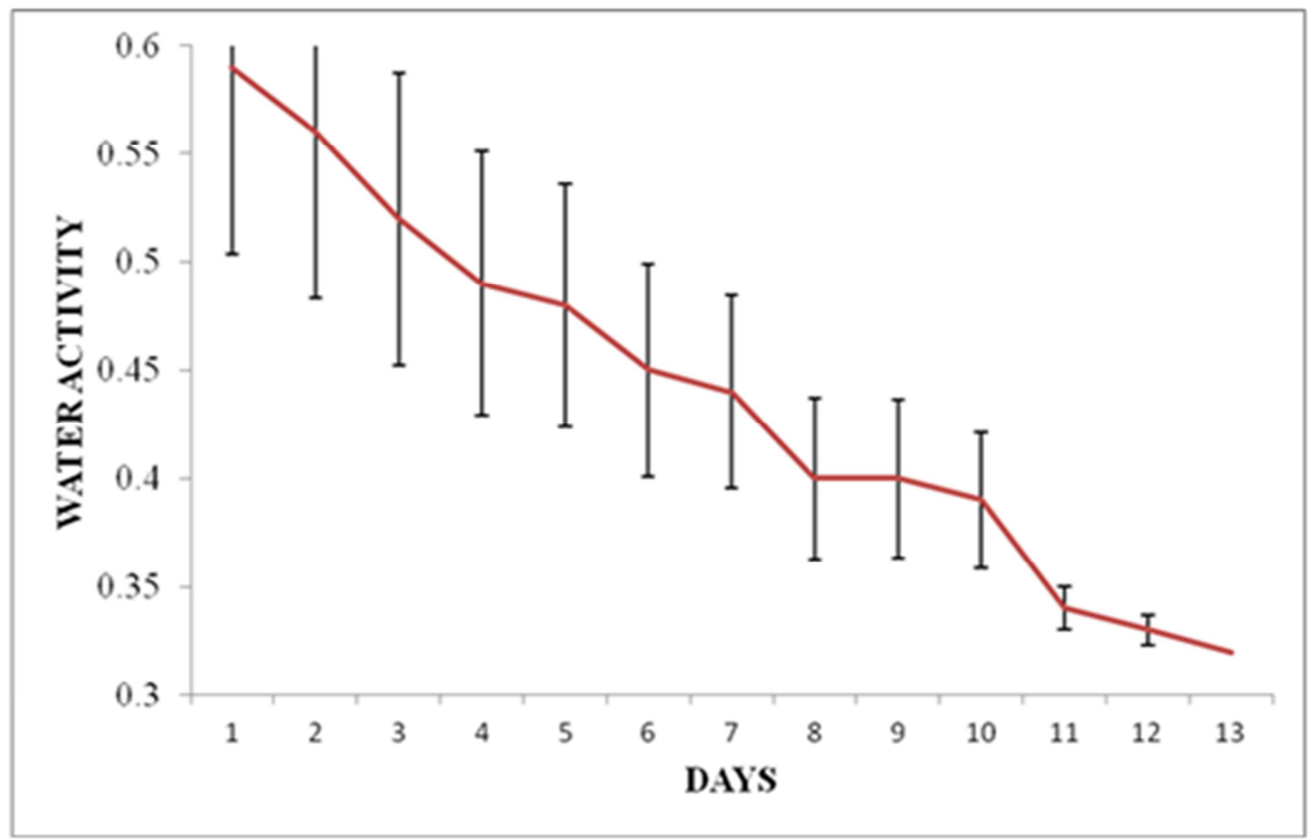

Figure 3. Water activity of the stored biscuits.

\section{Discussion}

The biscuits baked in this study were made from locally available materials in Bushenyi and target to mitigate the common deficiencies in Bushenyi. It is, therefore, feasible to mix local materials into suitable proportions that can be baked into a nutrient-rich complementary biscuit

\subsection{Recommended Portions}

The recommended serving portions for the age groups were 3 biscuits $(66 \mathrm{~g}), 3.5$ biscuits $(77 \mathrm{~g}), 5$ biscuits $(110 \mathrm{~g})$ and 6 biscuits $(132 \mathrm{~g})$ for 8 months to 12 months, 12 to 24 months, 24 to 48 months and 48 to 59months of age respectively are relatively high compared to the recommended ration sizes for 6-12 months old infants $(40 \mathrm{~g})$ or 1-2 years $(60 \mathrm{~g})$ [15]. However, the big portions and number of servings collaborate with studies in Vietnam where two or three portions per day of $35 \mathrm{~g}$ each were recommended, and the products were sold by community volunteers to low-income mothers [16].

The big portions are suitable for children in western Uganda there is high tendency of early introduction of complementary foods and low exclusive breast feeding rates $[17,18]$. These portions will serve to improving the amount of complementary foods consumed considering the children are breast fed less but still allows for the intake of other complementary foods. The portions can be served in more than one serving (two servings). The two servings are in agreement with feeding frequencies for breast fed infants $(2$ to 4 times) and non-breast fed infants (4 to 5) [19].

This study recommends that the biscuits are taken like other complementary food supplements. They should be added to the usual staple cereal porridges given to the children. This is sought to make the porridges semi-solid but also still allow the children to conform to usual complementary foods diets.

\subsection{Energy Density}

The energy density was $479.1 \mathrm{Kcal} / 100 \mathrm{~g}(4.79 \mathrm{Kcal} / \mathrm{g})$ which is in agreement with the typical complementary formulated biscuits which are expected to have a minimum of $4 \mathrm{Kcal} / \mathrm{g}$ of energy [13].

The serving of the formulated biscuits in this study are suitable for non-breast fed children ( 8 to 59 months) who are recommended to take a meal that provides $1.5 \mathrm{Kcal} / \mathrm{g}$ to $2 \mathrm{Kcal} / \mathrm{g}$ per serving [13].

Compared to the common cereal porridges given as infant complementary foods, the biscuit has a high energy density. Therefore instead of diluting the highly viscous porridges with large volumes of water, the biscuit could be added to the porridges. Therefore, the biscuit will not necessarily replace the common cereal porridges nor seek to adjust the preparation methods but could improve the viscosity of the porridges.

\subsection{Micro-Nutrients}

\subsubsection{Vitamin $A$ and $B_{12}$}

Vitamin $\mathrm{A}$ is the most common deficient vitamin among infants in Uganda up to $33 \%$ [1]. Whereas Vitamin A is mostly present fruits and vegetables, Vitamin $\mathrm{B}_{12}$ can only be found in animal products; milk and eggs. The Retinol Activity Equivalency (RAE) of the biscuit was $0.1 \mathrm{mg} / 100 \mathrm{~g}$ of the biscuit. This is thought to have been contributed by beta carotenoids from carrots; the Harvest Plus method only extracted beta carotenes from the biscuit samples. However, blue band margarine used in the study as a baking fat was fortified with Vitamin A $(100 \mu \mathrm{g} / 100 \mathrm{~g}$ of the margarine) which supplements the vitamin A levels in the biscuits. 
Vitamin A in the margarine is stable upon storage and baking [20]. This vitamin A therefore contributes to the obtained RAE value of the biscuit, thus meeting the $50 \%$ RDA for the different age group.

Vitamin $\mathrm{B}_{12}$ deficiency is common in developing countries, and it has been found to be high among diabetic patients [21] and HIV positive children [22] in Uganda. Local foods rich in Vitamin $\mathrm{B}_{12}$ were difficult to incorporate into the dough since it is mostly present in animal sources like offals, eggs and liver. The amount of the egg yolk added to the dough was limited by its contribution to fat and protein: the egg yolk has a lot of fat which when present in excess in complementary foods may be unhealthy.

However, in other studies, to improve vitamin $\mathrm{B}_{12}$, meat biscuits were developed to increase the animal protein intake in HIV-infected women and children in Kenya [23]. However, the shelf life of the biscuits was very low. We recommend fortification of banana flour with vitamin $B_{12}$ to allow increase in the levels of the vitamin in the biscuit without hampering the shelf life.

\subsubsection{Minerals}

Minerals Zinc and Iron are very crucial in the growth of infants [24]. They are, however, often deficient in the diets of children in Uganda [25].

The formulated biscuit had $4.46 \mathrm{mg} / 100 \mathrm{~g}$ of iron which is covers up to $30 \%$ RDA in the younger age groups and $50 \%$ RDA in older age groups. The coverage in older age groups is in line with 45 to $100 \%$ of iron recommended in formulated complementary foods [18]; however, the bioavailability of iron needs to be studied.

The biscuits had $2.14 \mathrm{mg} / 100 \mathrm{~g}$ of zinc which is covers up to $30 \%$ RDA in younger age groups and $50 \%$ RDA in older age groups. The coverage of RDA in the older age groups in line with 45 to $100 \%$ of zinc recommended in formulated complementary foods [18]. Since zinc is strongly chelated by phytic acid rendering the bioavailability of zinc low [14]; the content of phytic acid present in the biscuit needs to be studied.

\subsection{Shelf-Life Stability}

Thirteen days of storage of the biscuits under domestic storage conditions (closed cupboard) at room temperature was done to mimic the storage environment of rural mothers [26]. The moisture content increased while the water activity decreased with storage time.

\subsubsection{Moisture Content}

The moisture content of the formulated biscuit the first day after baking was in range for typical baked products $(2.3 \%)$ [13]. A similar trend of increase in moisture content was observed in an earlier study in biscuits stored in closed air, and attributed to the hygroscopic nature of fresh biscuits [28]

The increase in moisture content could be also attributed to auto-oxidation of fats as time in storage progressed [13]. Since biscuits are generally a hygroscopic food [27], it is important that its antioxidant activity is increased to prevent auto-oxidation of fats during storage.

\subsubsection{Water Activity}

The formulated complementary biscuit had a water activity of $0.59 \mathrm{~g}$ water/g substance. A water activity of below 0.61 is generally acceptable for baked products since it prevents the growth of yeasts and molds [19]. The observed decrease in water activity is also seen in biscuits with visible sugar crystals on their surfaces which have more hygroscopic tendencies at high temperature $\left(30^{\circ} \mathrm{C}\right)$. This decrease in $\mathrm{a}_{\mathrm{w}}$ is typical of some low-molecular weight substances such as crystalline sugar [13]. The use of granulated sugar during baking could explain the partial evaporation of the crystals reducing water activity of the biscuit. Use of granulated sugar, therefore, could lead to a decrease in water activity; decrease in water activity up to 0.36 allows for no microbial growth therefore increasing the shelf life of the biscuit.

\section{Conclusion}

A raw mix including carrots, eggs, milk, pumpkin seeds, soya beans and banana flour gave a theoretical nutritive value exceeding the RDA for children 8 to 59 months old. A biscuit was obtained from composite flour consisting of $20 \%$ pumkin seed, $24 \%$ soybean, $24 \%$ wheat and $32 \%$ banana. The serving portions meeting 50\% RDA of micro and macronutrients are $3(66 \mathrm{~g}), 3.5(77 \mathrm{~g}), 5(110 \mathrm{~g})$ and $6(132 \mathrm{~g})$ biscuits for children 8 to 12,12 to 24,24 to 48 and 48 to 59 months old respectively. The serving portions provide better coverage of the RDA for children in the older age target groups than the younger ones.

\section{Recommendations}

The study recommended further investigation on the following: studies on fortification of banana flour with vitamin $\mathrm{B}_{12}$ to allow for the improvement on the vitamin $\mathrm{B}_{12}$ content in the biscuit, use of natural antioxidants so as to prevent autoxidation, studies on nutrient profiles, and levels of phyatates, bioavailability, sensory evaluation, viscosity and osmolarity need to be done.

\section{References}

[1] Uganda Demographic Health Survey (2014). Malnutrition in Uganda. Health and Nutrition Fact Sheet, Office of the Prime Minister, 2011-2014.

[2] Kikafunda JK, Agaba. E. and A. Bambona. (2014). Malnutrition amidst plenty; an assessment of factors responsible for persistent high levels of childhood stunting in food secure western Uganda. African Journal of Food Agricuulture, Nutrition and Development, 14 (5), 9288-9313.

[3] Kikafunda, J. Kakuramatsi. (1998). changes in the viscosity and energy density of weaning maize porridge on supplementation with groundnut paste and diary milk. National Agriculture and Research Organization. 
[4] Ssemukasa, E., and Kearney, J. (2014). Complementary feeding practices in Wakiso district of Uganda. African Journal of Food, Agriculture, Nutrition and Development, 14 (4), 9085-9103. https://doi.org/10.1111/evo.12596.

[5] Kikafunda, J. K., Lukwago, F. B., and Turyashemererwa, F. (2009). Anemia and associated factors among under-fives and their mothers in Bushenyi district, Western Uganda. Public Health Nutrition, $12 \quad$ (12), 2302-2308 https://doi.org/10.1017/S1368980009005333.

[6] Van der Pols-Vijlbrief, R., Wijnhoven, H. a H., Schaap, L. a, Terwee, C. B., and Visser, M. (2014). Determinants of proteinenergy malnutrition in community-dwelling older adults: a systematic review of observational studies. Ageing Research Reviews, 18, 112-31. https://doi.org/10.1016/j.arr.2014.09.001

[7] Bain, L. E., Awah, P. K., Geraldine, N., Kindong, N. P., Sigal, Y., Bernard, N., and Tanjeko, A. T. (2013). Malnutrition in Sub - Saharan Africa: Burden, causes and prospects. Pan African Medical Journal, 15, 1-9. https://doi.org/10.11604/pamj.2013.15.120.2535.

[8] Bechman, A., Phillips, R. D., and Chen, J. (2015). The use of nutrient-optimizing/cost-minimizing software to develop ready-to-use therapeutic foods for malnourished pregnant women in Mali. Food Science and Nutrition, 3 (2), 110-119. https://doi.org/10.1002/fsn3.175.

[9] Andrew K. Amegovu, Patrick Ogwok, Sophie Ochola, Peter Yiga, Juliet H. Musalima, E. M. (2013). Formulation of sorghum-peanut blend using linear programming. Journal of Food Chemistry and Nutrition, 01 (02), 67-77.

[10] National Academy of sciences. Of America (2005), recommended dietary allowances / RDA Recommended Dietary Allowances Food and Nutrition Board, National Academy of Sciences - Recommended Dietary Allowances, Revised 1989.

[11] Kimura, Rodriguez.-Amaya and B. Deila (2004). Harvest Plus Handbook for Carotenoid Analysis. Harvest Plus Technical Monographs, 59.

[12] Michaelsen, K. F., Hoppe, C., Roos, N., Kaestel, P., Stougaard, M., Mølgaard, C., ... Friis, H. (2009b). Choice of foods and ingredients for moderately malnourished children 6 months to 5 years of age. Food and Nutrition Bulletin, 30 (3).

[13] Libor Cervenka, Iveeta Brozkova, J. V. (2006). Effects of the principal ingredients of biscuits upon water activity. Journal of Food and Nutrition Research, 45 (1), 39-43.

[14] Michaelsen, K. F., Hoppe, C., Roos, N., Kaestel, P., Stougaard, M., Mølgaard, C., ... Friis, H. (2009a). Choice of foods and ingredients for moderately malnourished children 6 months to 5 years of age. Food and Nutrition Bulletin, 30 (3).

[15] H. Allen, Lindasay. (2003). Nutrient Composition for Fortified Complementary Foods Proposed Nutrient Composition for Fortified Complementary Foods Food nutrition bulletin 1, 3011-3020.

[16] Peres, A. M., Alejandra, G., Parra, M., Lebres, V. F., Abeshu, M. A., Lelisa, A., and Geleta, B. (2016). Complementary Feeding: Review of Recommendations, Feeding Practices, and Adequacy of Homemade Complementary Food Preparations in Developing Countries - Lessons from Ethiopia. Front. Nutr, 3 (3), 413389-41. https://doi.org/10.3389/fnut.2016.00041.
[17] Poggensee, G., Schulze, K., Moneta, I., Mbezi, P., Baryomunsi, C., and Harms, G. (2004). Infant feeding practices in western Tanzania and Uganda: Implications for infant feeding recommendations for HIV-infected mothers. Tropical Medicine and International Health, 9 (4), 477-485. https://doi.org/10.1111/j.1365-3156.2004.01214.x.

[18] Ssemukasa, E., and Kearney, J. (2014). Complementary feeding practices in Wakiso district of Uganda. African Journal of Food, Agriculture, Nutrition and Development, 14 (4), 9085-9103. https://doi.org/10.1111/evo.12596.

[19] Gain. (2003a). Nutritional Guidelines for Complementary Foods and Complementary Food Supplements. Global Alliance For Improved Nutrition, 1, 1-23.

[20] Mahmoud, S., Butt, M. S., Anjum, F. M., and Nawaz, H. (2008). Baking and storage stability of retinyl acetate (Vitamin A) fortified cookies. Pakistan Journal of Nutrition, 7 (4), 586 589. https://doi.org/10.3923/pjn.2008.586.589.

[21] George Patrick Akabwai, Davis Kibirige, Levi Mugenyi, Mark Kaddu, Christopher Opio, Rejani Lalitha, Edrisa Mutebi and Martha Sajatovic (2016). Vitamin B12 deficiency among adult diabetic patients in Uganda: relation to glycaemic control and hemoglobin concentration. Journal of Diabetes \& Metabolic Disorders (2016), DOI 10.1186/s40200-016-0250-x.

[22] Grace Ndeezi, James K Tumwine Christopher M Ndugwa, Bjørn J Bolann and Thorkild Tylleskär (2011), multiple micronutrient supplementation improves vitamin $\mathrm{B}_{12}$ and folate concentrations of HIV infected children in Uganda, a randomized controlled trial. Nutrition Journal http://www.nutritionj.com/content/10/1/56.

[23] Ernst, J., Ettyang, G., and Neumann, C. G. (2014). Highnutrition biscuits to increase animal protein in diets of HIVinfected Kenyan women and their children: a study in progress. Food and Nutrition Bulletin, 35 (4), S198-S204. https://doi.org/10.1530/ERC-14-0411.

[24] Gibson, R. S., Bailey, K. B., Gibbs, M., and Ferguson, E. L. (2010). A review of phytate, iron, zinc, and calcium concentrations in plant-based complementary foods used in low-income countries and implications for bioavailability. Food and Nutrition Bulletin, 31 (2), 134-146.

[25] Black, R. E., Victoria, C. G., Walker, S. P., Bhutta, Z. a, Christian, P., de Onis, M., Uauy, R. (2013). Maternal and child under- nutrition and overweight in low-income and middleincome countries. Lancet, 382 (9890), 427-51. https://doi.org/10.1016/S0140-6736 (13) 60937-X.

[26] Diukareva, G., Pak, A., and Gasanova, A. (2014). Determination of storage conditions for new biscuits using their sorption isotherms, Ukraine food journal 3 (2), 249-256.

[27] Dewey, K., Berger, J., Chen, J., Chen, C., De Pee, S., Huffman, S., Zlotkin, S. (2009). Formulations for fortified complementary foods and supplements: Review of successful products for improving the nutritional status of infants and young children. Food and Nutrition Bulletin, 30 (2), 239-255.

[28] Navaratne, S. B., and Senaratne, C. (2014). Controlling of Auto Oxidation Process of Soft Dough Biscuits Using Flavonoids Extracted from Green Tea (Camellia sinensis), 3 (4), 425-428. 